\title{
Access to institutional delivery of mothers in Adigrat town, northern Ethiopia
}

\author{
Kidane Tadesse, Addisu Haile, Michael Tezera, Alemtsehay Tewele \\ Department of Public Health, College of Health Sciences, Mekelle University, Mekelle, Ethiopia
}

Email address:

Kiducs98@yahoo.com (K. Tadesse)

\section{To cite this article:}

Kidane Tadesse, Addisu Haile, Michael Tezera, Alemtsehay Tewele. Access to Institutional Delivery of Mothers in Adigrat Town, Northern Ethiopia. American Journal of Nursing Science. Vol. 3, No. 5, 2014, pp. 87-90. doi: 10.11648/j.ajns.20140305.15

\begin{abstract}
Background: Institutional delivery has a great role in reducing maternal and child mortality. Yet maternal mortality remains a major challenge to health system worldwide. And the Maternal mortality rate in Ethiopia continues to be an acceptable high level. The main aim of this study is to assess the level of access to health institution for maternal delivery and identify the underlying reasons. Methods: We have use community based cross sectional study design, data was collected using structured interview from mothers who have at least one delivery with the last five years. Data was entered and analyzed using SPSS, descriptive statistics were performed results are presented in terms of Frequency and percentage. Result: Majority $179(75.8 \%)$ were in an age range of 18 - 35 years. Majority $208(88.1 \%)$ of our study subjects were attended antenatal care (ANC) follow up and majority of them 160(77.3\%), 38(18.4\%) and have followed ANC four times throughout their last pregnancy. Out of 208 respondents attended ANC follow up, 185(89.4\%) have received all the necessary in formations, advice on birth preparedness and complication readiness. Of those who have no ANC follow up $28(11.9 \%)$, half of them were due to reason that they have no any problem in their pregnancy and the other are due to too far distance home to health facility $5(17.8) \%$. Majority, 201(85.2\%) were delivered at health institution. The most common reasons for home delivery were normal previous delivery, labor at night, comfort at home, unwelcoming approaches of health workers. Conclusion: Institutional delivery coverage of the study area is good which $85.1 \%$ in the last five years. The ANC coverage $88.1 \%$ of the area is not proportional with the institutional delivery $85.1 \%$ which indicates that there is a gap in health education during ANC follow up especially about birth preparedness and complication readiness.
\end{abstract}

Keyword: Maternal Health, Delivery, ANC, Ethiopia

\section{Background}

Globally, 287,000 mothers die from complications of pregnancy and childbirth. Sub-Saharan Africa and Southern Asia accounted for $85 \%$ of the global burden of maternal deaths [1]. The rate of maternal mortality in Ethiopia is one of the highest in the world and estimated 673 maternal deaths per 100,000 live births in 2012 [2]. Most maternal deaths are avoidable, as the health-care solutions to prevent or manage complications are well known. It is particularly important that all births are attended by skilled health professionals, as timely management and treatment can make the difference between life and death [3].

Over 30 million women in the developing world suffer from serious diseases and disabilities which include; uterine prolapsed, pelvic inflammatory disease, fistula, incontinence, infertility, and pain during sexual intercourse as a result of inadequate or inappropriate care during pregnancy, delivery or the first critical hours after birth (4).

In addition to the above consequences, maternal death has also an impact in the health and well-being of families, communities and in general in the social and economic situation of the societies. Each year an estimated US \$15.5 billion is lost in potential productivity when mothers and newborns die (5). When a woman dies in childbirth, her infant and any other children's survival is threatened. Infants without mother are more likely to die within two years. Children up to 10 years whose mothers die are 3 to 10 times more likely to die within two years than children living with mothers. Every year an additional 2 million children worldwide are maternal orphans (6). Maternal death has long term effects on a child's education and health. When a mother dies, older children often leave school to support their family. Children without a mother are less likely to be immunized and are more likely to 
suffer from malnutrition (7).

Recent efforts to reduce maternal mortality in developing countries have focused primarily on training and deploying skilled birth attendants and upgrading emergency obstetric care facilities and also training traditional birth attendants, community health workers, and provision of linkages between different health facilities and communities are constructed key strategies to reduce maternal mortality [8]. However, the proportion of birth attended by skilled health workers varies across the regions. Nearly all births in developed countries, $61.9 \%$ in less developed countries, $35.3 \%$ in the least developed countries and $33.7 \%$ births in eastern Africa were attended by skilled health personnel [9].

As Previous local studies done in Ethiopia showed that there were variation in skilled birth attendance, $12.3 \%$ in Munisa district [10], 4.3\% of rural mothers and $40 \%$ urban mother ,in Arsi [11], 12.0\% (20.8\% in urban and 6.8 \% in rural mother) in Metekel [12], 13.5\% in North Gondar [13], 12.1\% in Sekela district [14].

In Ethiopia institutional delivery service utilization at national level was very low; $94 \%$ of mothers were delivered at home and the rest: $5 \%$ of births were delivered at a public facility and less than $1 \%$ of births in private facility (15). Only $10 \%$ of births were assisted by skilled health care provider. Moreover, sixty one percent of mothers stated that health facility delivery was not necessary and thirty percent stated that it was not customary to deliver at health facility [2].

As evidenced from previous studies institutional delivery service utilization were associated with educational status of mothers and their husbands, income level, preferences of the attentions of their relatives, trust on traditional birth attendants, absence of health problems during pregnancy, ante- natal visits during pregnancy, short duration of labor, mothers' place of residence, age, perceived distance to the nearest health facility and transportation costs [10-14].

Every day, at least 1,600 women die worldwide from the complications of pregnancy and childbirth, $90 \%$ of which occurring in Asia and sub-Saharan Africa. Maternal mortality rate was shown to have the largest discrepancy between developed and developing countries, among others (16-18). A lifetime risk of maternal death in developing countries is forty times higher than that of the developed world $(16,17)$.

Maternal mortality rate in Ethiopia continuous to be an acceptable high level, estimated to 2.9 million women gave birth every year, of those approximately 25000 women and girls die each year and more than 500,000 suffer serious injuries and permanent damage to their health, such as uterine prolapsed, obstetrics fistula(i.e. vesicle vaginal or recto vaginal fistula). it estimates that 100,000 women suffer with un treated fistula across the country and another 9000 women develop fistulas every year which are mainly caused by obstructed labor and lack of maternal health care(19). furthermore obstructed labor can also result in infections, including sepsis, pelvic inflammatory diseases(PID) which damage the reproductive system leading to infertility and range of gynecological disorders $(16,17,20)$

According the Ethiopian health survey Maternal mortality rate in Ethiopia were $673 / 100,000$ live births (15), $549 / 100,000$ live births (2).majority of maternal death are clustered around labor, delivery) and immediate post-partum period Met lab Bangladesh).labor/delivery, and the first day being the highest.

The main causes of maternal death are classified as direct obstetrics and indirect obstetrics causes. The direct obstetric causes accounts around $80 \%$ of the maternal mortality and they are due to complication that develops directly as a result of pregnancy, delivery or post-partum period where as the indirect obstetric cause which accounts around 20\% of maternal death are due to complications that are made worse by pregnancy or delivery e.g. malaria, HIV/AIDS(21). In Ethiopia are abortion (32\%), obstructed labor (22\%), sepsis $(12 \%)$, hemorrhage (10\%), hypertension (9\%) and other direct causes $(15 \%)$. Between $11 \%$ and $17 \%$ of the deaths occurred during the delivery and between $50 \%$ and $71 \%$ in postpartum period. About $45 \%$ of postpartum death occurs during the first twenty four hours and greater than $2 / 3$ during first week (21).

\section{Methods and Materials}

The study was conducted in Adigrat town which is located at $121 \mathrm{~km}$ from Mekelle, the capital city of Tigray Regional State. Adigrat has two health centers and one hospital and three higher private clinics. Community based descriptive cross sectional study was conducted including mothers who gave birth in the last five years. The data was collected by structured questionnaire using interview. Data was entered to SPSS 16.0 analyzed and organized by frequency and percentage.

Ethical approval was obtained from Mekelle University, College of Health Sciences. Permission was also obtained from Adigrat town administration office. The purpose of the study was explained to the study participants and verbal consent was obtained from them during the interview and confidentiality was also assured during the data collection process. Their privacy was also maintained and they were informed that the information obtained from them was not affecting their future life.

\section{Results}

Socio demographic characteristics

Majority $179(75.8 \%)$ were in an age range of $18-35$ years and the rest $48(20.4 \%)$ and $9(3.8 \%)$ were above 35 years and below 18 years respectively. From the interviewed mothers, 193(81.8\%) are Orthodox, 23(9.7\%) Catholic, 11(4.7\%) Muslims and the remaining 9(3.8\%) are protestant. Among the 236 mothers, 199(84.3\%) are Tigray, $32(13.6 \%)$ are Erope and the remaining 5(2.1\%) are Amhara of ethnicity.

\section{Past obstetrics history}

Out of the total respondents 42 (17.8\%), 194(82.2\%) were got their first marriage in the age of below 18 and above 18 years respectively and majority of them 229 (97\%), were got their first pregnancy in the range age of $18-35$ yrs. Majority 
of the total respondents $228(96.6 \%)$ were in the range age of 18-35 years for their last pregnancy. About 104 (44\%), $92(39 \%)$, and $40(17 \%)$ of the total respondents responded that they are gravida, 1-2, 3-4 and $>4$ respectively and $149(63.1 \%)$ gave birth once, $82(34.7 \%)$ two times and $5(2.2 \%)$ more than two times within the past five years. Out of the total respondents $25(10.6 \%)$ and $13(5.6 \%)$ reported that they were encountered at least once abortion and still birth respectively in their life time. According to this study $208(88.1 \%)$ of our study subjects were attended ANC follow up and majority of them $160(77.3 \%), 38(18.4 \%)$ and $9(4.3 \%)$ have followed ANC four times, 2-3 times and once only respectively throughout their last pregnancy. Out of 208 respondents attended ANC follow up, 185(89.4\%) have received all the necessary in formations, advice on birth preparedness and complication readiness. Of those who have no ANC follow up 28 (11.9\%), half of them were due to reason that they have no any problem in their pregnancy and the other are due to too far distance home to health facility $5(17.8) \%$, their husband were not allowed $3(10.8 \%)$, $6(21.4 \%)$ were do not know its advantage.

Table 1. Socio demographic characteristics of respondents in Adigrat town, 2014

\begin{tabular}{|c|c|c|c|}
\hline Variables & & Frequency & Percentage \\
\hline \multirow{3}{*}{ Age } & $<18$ year & 9 & 3.8 \\
\hline & 18-35year & 179 & 75.8 \\
\hline & $>35$ year & 48 & 20.4 \\
\hline \multirow{3}{*}{$\begin{array}{l}\text { Marital } \\
\text { Status }\end{array}$} & Married & 219 & 92.8 \\
\hline & Divorced & 11 & 4.7 \\
\hline & Widowed & 6 & 2.5 \\
\hline \multirow{3}{*}{$\begin{array}{l}\text { Family } \\
\text { Size }\end{array}$} & $1-3$ & 95 & 40.3 \\
\hline & $4-5$ & 110 & 46.6 \\
\hline & $>5$ & 31 & 13.1 \\
\hline \multirow{4}{*}{$\begin{array}{l}\text { Monthly } \\
\text { In come } \\
\text { Educational } \\
\text { status }\end{array}$} & $<500$ Birr & 17 & 6.4 \\
\hline & $500-1000$ Birr & 58 & 24.8 \\
\hline & $>1000$ Birr & 161 & 68.8 \\
\hline & & & \\
\hline \multirow{9}{*}{ Occupation } & Unable read and write & 41 & 17.6 \\
\hline & Read and write & 28 & 12 \\
\hline & Elementary & 47 & 19.8 \\
\hline & High school & 73 & 30.8 \\
\hline & College and above & 47 & 19.8 \\
\hline & Housewife & 97 & 41.1 \\
\hline & Government employed & 47 & 19.9 \\
\hline & Self employed & 78 & 33.1 \\
\hline & Farmer & 14 & 5.9 \\
\hline
\end{tabular}

\section{Practices of institutional delivery}

According to this study, out of 236 mothers of our study subjects who gave birth at least once in the last 5 years, 201(85.2\%) were delivered at health institution and the rest $35(14.8 \%)$ were delivered at home .out of the total home deliveries, $13(37.1 \%)), 11(31.4 \%), 9(25.7 \%)$ of $2(5.7 \%)$ of the deliveries were assisted by neighbors, UTTBA, family members (mother) and TIBA respectively.

The most common reasons for home delivery were normal previous delivery19 (54.3\%), labor at night $9(25.7 \%)$, comfort at home $3(8.6 \%)$, unwell coming approaches of health workers $2(5.7 \%)$, and precipitate labor 2(5.7\%). Most mothers who gave birth at home16 $(45.7 \%)$, reported that they experience complications, PPH7 (43.8\%), prolonged labor5 (31.2\%) and retained placenta4 (25\%).

Concerning decision making for delivering in the health facility, predominantly it was a joint decision by the mother and her husband119 (59.2\%) while 61(30.3\%) reported that they decided by themselves and 14(7\%) mothers said that the sole decision making power was that of their husbands and mothers and the remaining $7(3.5 \%)$ were by health professional decision. All most all of the mothers of our study subject 229(97.1\%), told us they preferred to deliver on health institution and to be assisted by health workers for their next delivery and the rest $7(2.9 \%)$ mothers said that they didn't want to deliver in future.

\section{Discussion}

This study shows that institutional delivery service utilization in the study area was high as compared to institutional delivery in Ethiopian demographic and health survey( EDHS 2011) which is $10 \%$ (22). Other studies, conducted in Sekela 12.1\% (14), north Gonder 13.5\% (13) and in Munisa district $12.3 \%$ (10). This might be due to high ANC coverage in which there is a good counseling about birth preparedness and complication readiness and, the near availability of health facility. Majority of the mothers preferred institutional delivery $(85.2 \%)$. The most common reason for home deliveries were, normal previous labor $54.3 \%$, labor at night $25.7 \%$ unwelcoming approach of health workers $5.7 \%$,short labor(precipitate labor) $5.7 \%$ and comfort at home $8.6 \%$. Similar studies from Arsi revealed that the main reasons for home deliveries were short labor (54.8\%) (11), in north Gondar short labor (42\%), need to be attended with relatives during labor (44.7\%) (13)

In the study area despite that ANC coverage is high $88.1 \%$, all mothers who had ANC visit did not give birth at health facility $(85.1 \%)$. This might be due to the reason that during ANC, mothers did not get enough information about the risk of home delivery. On the other hand mothers can come for ANC by themselves, but they could not come when they are in labor because of they need the help of others.

The institutional delivery coverage was found to be good, which is $85 \%$ in the last five years. About $88.1 \%$ of mothers who were delivered in the last five years have attended ANC follow up at least once for their last pregnancy. The ANC coverage $88.1 \%$ of the area is not proportional with the institutional delivery $85.1 \%$ which indicates that there is there a gap in health education during ANC follow up especially about birth preparedness and complication readiness. 


\section{References}

[1] World Health Organization: trends in maternal mortality: 1990-2010 estimates developed by WHO,UNFPA and the world bank. Geneva 2012

[2] Central statistical agency [Ethiopia] and ICF International: Ethiopia demographic and health survey 2011: Addis Ababa. Ethiopia and Calverton .Marviand.USA: central statistical agency and ICF

[3] World Health Organization: Maternal mortality (2012)url:http/www.who.int/mediacentte fact sheets/fs348/en/index. html

[4] Nawal M. Nour (2008).an introduction to maternal mortality .Reviews in obstetrics and gynecology (2):77-81.

[5] Edward. E.N ketiah-Amponsah (2009) expectant mothers and the demand for institutional delivery; Do household income and access to health information. some insight from Ghana. European journal of social science. 8.3.

[6] World health organization (2005).maternal mortality fact sheets. www.who org.Accessed on June 25, 2009.

[7] WHO. World health organization (2005).facts sheets maternal mortality.

[8] Prata L.passano P. rowel Bells Walsh J.and Potts Where there are (few birth attendants).J0urnal of health nutrition. Population

[9] Department of Reproductive health and research: proportion of births attended by a skilled birth worker by WHO Geneva; $2008 \quad$ updates.url:http//www.who.int/reproductive health/publications maternal-perinatal-health/2008-skilled attendant.pdfl:

[10] Amano A, Gebeyehu A and Birhanu Z: institutional service utilization in monisa wereda, south east Ethiopia: a community based cross sectional study, BMC pregnancy child birth 2012, 12:105.

[11] AberaM, G/mariamA, and Belachew T: predictors of safe delivery utilization in Arsi zone, south east Ethiopia Journal of health sciences: 2011: yol. 21, special issue: 101-13.

[12] Tura G, G/mriam: safedelivery service utilization in in Metekel zone, North West Ethiopia. Ethiopia Journal of health science. 2011:17(4):233-222.

[13] Nigussie M, D,Mitike G: assessment of safe delivery utilization among mothers of child bearing age in north Gonder zone, North West Ethiopia. Ethiopian Journal health development.2004; 18(3):145-152.

[14] Tefera AS, Alemu FM, weldeyowahns SM: Institutional service utilization and associated factors among mothers who gave birth in the last 12 months in sekela district North West of Ethiopia community based cross sectional study BMC pregnancy and child birth 2012,12(74):1-11

[15] Central statistical [Ethiopia] and Ethiopia demographic health survey2005: Addis Ababa, Ethiopia and Calverton .Maryland USA: central statistical agency and ICF international.

[16] WHO. UNICEF and UNFPA. Maternal mortality in 1995; estimates developed by WHO/UNICEF, Geneva, 2001.

[17] Omar MM. women's health in rural Somali licentiate Dissertation, 1994

[18] World health organization UNICEF/. Revived 1990 estimates of maternal mortality: Anew approach by world health organization Geneva, 1996.

[19] Federal Minister of health, health and health related indicators, 2005, Addis Ababa.

[20] UNICEF.progress on maternal mortality, Geneva, 1996.

[21] WHO (2005) causes of maternal mortality. WWW.Maternity world wid.org.

[22] Central statistical agency[Ethiopia] and ORC MACRO 2011 "Ethiopia Demographic and health survey 2011" Addis Ababa, Ethiopia. 